\title{
A IDENTIDADE VAZIA OU O SI-MESMO COMO NADA (Z, PERSONAGEM DE UM CONTO DE JULIANO PESSANHA)
}

\author{
Annita Costa Malufe
}

Resumo: A partir do conceito de identidade narrativa, formulado por Paul Ricoeur, o artigo busca apresentar o personagem Z, do conto “Deslocamentos”, de Sabedoria do Nunca, de Juliano Pessanha. O objetivo é mostrar como esta narrativa nos traz um caso exemplar daquilo que Ricoeur define como identidade-ipse, ou “ipseidade”. Um caminho que nos levaria, assim, a problematizar uma nova forma de subjetividade, bastante característica do cenário contemporâneo.

Palavras-chave: Literatura contemporânea. Identidade narrativa. Paul Ricoeur.

Abstract: With the concept of narrative identity formulated by Paul Ricoeur as a starting point, this article presents the character Z, of "Displacements" ["Deslocamentos", in Sabedoria do Nunca], a short story by Juliano Pessanha. The objective is to show how this narrative displays an exemplary case of what Ricoeur defines as identity-ipse, or "ipseism". This would enable us to analyze a new form of subjectivity, characteristic of the contemporary scenery.

Keywords: Contemporary literature. Narrative identity. Paul Ricoeur.

Introdução

Seria possível conceber uma identidade pessoal que fugisse dos grandes fardos que nos impõe a tradição metafísica - a saber: a unidade, a semelhança, a continuidade, a permanência no tempo? Como falar em identidade fora deste registro da "mesmidade" ao qual somos constantemente submetidos, tanto no senso comum quanto ao longo de nossa história da filosofia?

No quadro desta inquietação, Paul Ricoeur propõe: no lugar da identidade-idem que estamos acostumados a pensar, deveríamos nos esforçar por conceber uma identidade-ipse. Ao invés de uma identidade como mesmidade, uma identidade como si-mesmo, como ipseidade.

\footnotetext{
"Doutora em Teoria e História Literária pela Unicamp.

${ }^{1}$ Refiro-me às idéias desenvolvidas em O si-mesmo como um outro e nos dois artigos "L'Identité Narrative" (In: Esprit e Revue des Sciences Humaines).
} 
O ponto de partida é a ambigüidade semântica contida na própria raiz da noção de identidade - o idêntico que, em latim, tanto pode significar "idem" quanto "ipse”. Idem: extremamente parecido, semelhante, análogo - concepção que teria prevalecido ao longo da história do pensamento ocidental. Compreender a identidade como idem implica em crer na existência de uma substância imutável em cada coisa, uma espécie de núcleo duro, fixo, atemporal, que seria responsável pela identificação. Implica também em crer na imediaticidade do sujeito de conhecimento, tal como no "cogito" cartesiano - a presença plena de um Eu enorme que pensa antes de existir, o primado de uma consciência plena e fechada em si, capaz de preceder sua própria existência.

Como bem remarca Jeanne-Marie Gagnebin, em seu artigo "Uma filosofia do cogito ferido: Paul Ricoeur”, há uma forte crítica em Ricoeur ao idealismo filosófico mais exacerbado, em especial no que se refere à autosuficiência da consciência. E então, é neste esforço de escapada a toda uma tradição filosófica do "penso logo existo", esforço que em Ricoeur passa pelo diálogo com Husserl e Heidegger (mas também Lévinas, outro filósofo que tanto dialogou com eles), que se insere a tentativa de delinear o que seria uma identidade-ipse, uma identidade do si-mesmo que se constitui com o outro.

Assim, não se trata mais de um Eu que engole toda a experiência e preexiste a ela, mas sim de um si-mesmo em constante construção e criação de si. Como diz Gagnebin (1997, p.262), este seria um dos temas centrais no pensamento de Ricoeur: a tentativa de refletir sobre "a não-soberania do sujeito consciente e sua relação simbólica e cultural com esse outro que lhe escapa”. Na identidade-ipse, o outro é constitutivo e o processo de individuação é constante e nunca algo acabado.

Se a metafísica tradicional perguntava-se pelo sujeito a partir da questão “o quê é?”, à qual teríamos uma resposta da ordem da mesmidade, na investigação da identidade-ipse, Ricoeur (1991) propõe o deslocamento dessa questão. Desse modo, não devemos mais nos perguntar pelo "o quê" mas sim pelo "quem”. Diferentemente do "o quê", que parece apontar para a suposição de um núcleo fixo, atemporal, a pergunta pelo "quem" remete obrigatoriamente às ações - “quem fez x ou y?” - e as ações, é importante marcar, dão-se obrigatoriamente no tempo: Nossa tese constante será que a identidade

\footnotetext{
${ }^{2}$ Ricoeur refere-se tanto ao conceito aristotélico de substância quanto ao Eu transcendental de Kant, no qual também se faz presente a idéia da prioridade da substância sobre os acidentes. 
no sentido de ipse não implica nenhuma asserção concernente a um pretenso núcleo não-mutante da personalidade. (RICOEUR, 1991, p.13).

Entra em jogo uma indagação que é imediatamente remetida ao "si”, ao agente das ações. Perguntar "quem” implica em se perguntar não somente pela ação, estas que se dão no tempo, mas sobretudo pela ligação do sujeito com estas ações, logo, com sua própria temporalidade. Trata-se de um si que se define a partir de suas ações e que, portanto, se define não apenas no tempo mas com o tempo, inseparavelmente dele.

Claro que não temos como desenvolver aqui todas as nuances desta complexa noção, que tanto se inspira na concepção ontológica de Heidegger (especialmente em Ser e Tempo). No entanto, creio que valeria assinalar mais um ponto: deslocar o entendimento da identidade para a ação e seu agente tampouco implicaria somente em definir o sujeito por suas ações, pelos fatos empíricos de sua vida. Ricoeur inclusive critica a posição da filosofia analítica, uma vez que a identidade para ele não pode ser vista apenas como o que se descreve de alguém, apenas os fatos em si. "O si, eu diria, não pertence simplesmente à categoria dos acontecimentos e dos fatos”. (RICOEUR, 1988, p.299).

É importante notar que, na ipseidade, não se trata de dizer simplesmente que fulano é aquilo que ele fez, mas sim, e sobretudo, de buscar qual a relação que ele assume com aquilo que ele fez. Trata-se antes, portanto, de uma pergunta pelo sentido de determinada ação para seu agente. Questionamento que coloca na mesa o problema da responsabilidade - quem responde pelo que foi feito?

\section{Identidade narrativa}

Particularmente aqui, vai interessar-me o fato de que, para pensar este intrincado problema da identidade pessoal, Ricoeur recorre à identidade narrativa. Para ele, a identidade narrativa poderia contribuir na "resolução das dificuldades relativas à noção de identidade pessoal” (RICOEUR, 1988, p.296), uma vez que na narrativa de ficção podemos observar exemplarmente esta "mistura de ispseidade e de mesmo" (RICOEUR, 1991, p.35), implicada em qualquer história de vida. Diz ele: "As variações imaginativas das narrativas de ficção dizem respeito à relação variável entre ispeidade e mesmidade 
(...)”(RICOEUR, 1988, p.302), permitindo-nos, assim, observar bem a dialética de permanência e mudança, de concordância e discordância que faria parte da dinâmica identitária.

Neste ponto, percebemos que os dois registros da identidade - como idem e como ipse - seriam coexistentes, como dois registros distintos que se cruzam e se alternam. E é bem esta dinâmica de alternância e cruzamento que a ficção literária poderia ajudar-nos a enxergar, a vivenciar.

No caso da narrativa literária também temos a vantagem de nos confrontarmos com uma identidade que é construída deliberadamente na intriga ou seja, vemos claramente que ali não se separam a identidade do personagem e a intriga, o enredo. Ambos coexistem, se interpenetram, interdependem, se constroem conjuntamente. É então, segundo Ricoeur, na própria intriga que devemos buscar a identidade narrativa. Falando em termos próprios de Ricoeur, a configuração da intriga e a figuração da personagem não podem ser pensadas sozinhas.

Na ficção literária, segundo Ricoeur, deparamo-nos com situações em que a ipseidade se dissocia da mesmidade. É o que ele chama de "casos embaraçosos" da literatura, aqueles que tendem a dissociar a pergunta ipse "quem" da resposta idem. Casos estes que se intensificam na literatura moderna, em que freqüentemente nos deparamos com casos de perda de identidade, com personagens portadores de uma frágil identidade-idem. Diz Ricoeur: "Quem é 'eu' quando o sujeito diz que ele não é nada? Precisamente um si privado da segurança da identidade-idem” (RICOEUR, 1988, p.303).

\section{Identidade vazia}

Encontro-me com um personagem exatamente assim, privado até o extremo de qualquer segurança da mesmidade; um quase não-personagem, um habitante do nunca. Personagem que "nem sequer tinha ingressado nos hábitos da história e nas aventuras do calendário" (PESSANHA, 1999, p.39). Encontro-me com Z, personagem sem rosto do conto "Deslocamento", de Sabedoria do Nunca (1999), de Juliano Pessanha.

Z é um personagem sem memória, sem história, sem superfície de registro. Z move-se no mundo como se a ele não pertencesse: "Desde peque- 
nininho, Z sentia-se tão irreal que se espantava em respirar”. (PESSANHA, 1999, p.31). Z move-se sem deixar marcas: "quando se consumasse o seu desaparecimento, ele estaria certo de não ter deixado nenhum rastro" (PESSANHA, 1999, p.31). Z vive em vias de desaparecer, assim como suas ações e seus movimentos. Todos são puros instantes que se dão e logo em seguida somem, como se nada tivesse acontecido. Sem vestígios, nem mesmo cicatrizes: Eu mesmo já o vi junto dessas pequenas coisas atiradas no centro de uma fogueira estéril e Z ficava quase gritando mas não conseguia ter queimaduras e não tinha para onde fugir. (PESSANHA, 1999, p.24).

Z, no entanto, tem uma "secreta ambição de ser real" (PESSANHA, 1999, p.26), sonha em ter algo que possa ligar um dia ao outro, sonha em ter um Eu. O Eu, que seria a identidade-idem, traria algo perene e substancial e este algo de fixo e atemporal seria paradoxalmente aquilo que permitiria a $\mathrm{Z}$ uma pertença ao mundo temporal dos homens - a este mundo da memória:

Habitado por algo indestrutível, Z iria ganhar um rumo no lado de dentro do mundo. Saberia o que é que liga um dia ao outro, e deixaria de ser apenas o assombro e o segredo dos lugares e, chorando pelas guerras, torcendo em olimpíadas e pondo espelhos no banheiro, estaria suficientemente pesado para atingir o raio das memórias e das esperanças. (PESSANHA, 1999, p.44).

Z não tem "o que liga um dia ao outro", e o que liga os vários fragmentos de ação que compõem esta estranha história é justamente esta falta de fixação do personagem, sua extrema estranheza frente ao mundo, seu deslocamento constante, ininterrupto. $Z$ sonha em conseguir ser humano, o que implicaria em ter hábitos e sentimentos humanos, participar da moral da humanidade, ter memória, histórias para contar.

Z entretanto é inteiramente vazio e o que o identifica é uma espécie de incapacidade para se completar, para conter as coisas que nele esbarram. Uma total incapacidade de permanência, de fixidez: "não havia dia longo o suficiente que não passasse por ele como um relâmpago”. (PESSANHA, 1999, p.38). Como conter o fluxo?, parece perguntar-se Z. Como fugir da "província do esvaziamento"? E uma das tentativas que lhe ocorre seria a de "imitar" os outros humanos, tentar forjar um ponto de fixação. Tentativa certamente vã, que apenas denuncia a exterioridade a que pertence $\mathrm{Z}$. 
Como contraponto ao protagonista Z, entra em cena um homem bêbado, contador de histórias. Um homem espaçoso, pesado, excessivamente humano, carregado de moral, memória e história, uma "criatura subjetiva, estupidamente real, dotada de tantas reminiscências vivas e de considerável dose de ser”. (PESSANHA, 1999, p.36). Este homem irrita Z profundamente, pois é um homem carregado de humanidade ao extremo, portador de uma identidade-idem bastante exemplar. É curioso vermos o contraponto entre os personagens, duas formas de "exílio", como diz o narrador: um exílio demasiadamente mundano, de um "dentro" insuportável, uma fixidez paralisante, e o exílio de Z, aquele que habita do lado de fora do mundo, da cultura. Exílio em fluxo contínuo, sem descanso.

Se pensarmos com Ricoeur que ao questionamento da identidade narrativa corresponde um questionamento da própria narratividade, de fato o que temos neste enredo é uma configuração tão caótica quanto a figuração da personagem Z. Faz extremo sentido pensamos que: À perda de identidade da personagem corresponde uma perda da configuração da narrativa e em particular uma crise de seu fechamento [clôture].

Temos em "Deslocamento" uma intriga nada convencional. Se tentarmos traçar em linhas gerais "o que se passa” na narrativa, poderíamos dizer que muito pouca coisa se passa efetivamente ali: um garoto (rapaz? criança?) está no metrô com sua mãe, indo a uma consulta no dentista quando, subitamente, se dá conta de que a mãe não está mais ao seu lado. Segue-se então uma procura da mãe, que não chega a ser bem uma procura, e Z acaba sendo levado a um bar onde se depara com o tal bêbado insuportável contando histórias, até que Z escapa por uma brecha do bar e o desfecho se dá em um único parágrafo final em que $Z$ de fato "desaparece" (um suicídio?), em uma cena com ares míticos, ritualísticos.

A intriga é construída pelos pensamentos inconclusos de Z, a narração de seu despertencimento e de suas tentativas de adequação em pequenas cenas banais mundanas. Há certamente aqui uma vizinhança do ensaio - o livro de Juliano Pessanha inclusive é composto por três partes: ficção, poemas e, por último, um ensaio filosófico, "O ponto K (Heidegger e a psicanálise)", no qual o leitor fica ciente da forte referência a Heidegger presente na literatura de Pessanha - vizinhança esta que aproxima ao que Ricoeur observa acerca

\footnotetext{
${ }^{3}$ Ricoeur, trecho que coincide em ambos artigos “L’identité narrative” - em Esprit , p.301 e em R.S.H., p.41. 
do romance moderno:

A erosão dos paradigmas atinge ao mesmo tempo a figuração da personagem e a configuração da intriga; assim, no caso de Robert Musil, a decomposição da forma narrativa paralela à perda de identidade da personagem faz atravessar as fronteiras da narrativa e joga a obra literária na vizinhança do ensaio. Tampouco seria por acaso se tantas autobiografias modernas, aquela de Leiris por exemplo, se desviam deliberadamente da forma narrativa e se juntam ao gênero literário o menos configurado, o ensaio precisamente.

Talvez em alguns aspectos possamos de fato aproximar a autobiografia de Michel Leiris, A Idade Viril, ao conto de Pessanha. Leiris compõe a intriga de sua "história de vida" a partir de fragmentos de reflexões, sonhos e de histórias da antiguidade e mitológicas. Não temos como produto final uma narrativa linear, que nos apresente uma identidade fechada de Leiris. Nem fechada tampouco "orgulhosa de si" - há também este ponto em comum entre Z e Leiris, uma espécie de inadequação ao mundo, de despertença fundamental. Narrativa de um sujeito que está longe de querer se auto-afirmar.

Paradoxalmente, o que assistimos nesta autobiografia é menos a constituição de uma identidade de Leiris, no sentido do mesmo, do que a configuração de um enredo, que nos leva a passear em diversos campos. Dito de outro modo, não temos a figuração de um Eu fechado, mas a construção de um mapa de caminhos deste alguém que nos narra seu percurso de mutações.

Da mesma forma que ocorre com Z, de Pessanha, não conseguimos, em Leiris, juntar a história nem a personagem em uma unidade totalizadora. A identidade se faz de percursos, traços, rastros de uma vida. É aqui a presença da ipseidade no lugar da mesmidade. Que algo permanece do Leiris que escreve hoje e que viveu as coisas que são narradas é um fato - como diz Ricoeur, o si-mesmo (ipse) e o mesmo (idem) se cruzam na questão da permanência no tempo - no entanto, não se trata da mesma permanência. O que nos cabe questionar é: qual é o tipo de permanência que concerne ao si? Acerca disso, tomo emprestado um belo trecho de Jean Starobinski, ao falar da autobiografia:

${ }^{4}$ Ricoeur, “L’identité narrative”, Esprit, p.301-302 - ou trecho quase idêntico em “L’identité narrative”, R.S.H, p.41, no qual consta: "gênero literário menos fixo que é aquele dos ensaios.”

Uniletras, Ponta Grossa, v. 30, n. 2, p. 399-408, jul./dez. 2008 
(...) c'est parce que le moi révolu est différent du je actuel, que ce dernier peut vraiment s'affirmer dans toutes ses prérogatives. Il ne racontera pas seulement ce qui lui est advenu en un autre temps, mais surtout comment, d'autre qu'il était, il est devenu lui-même. (STAROBINSKI, 1970, p.261).

Creio que é na narração deste percurso de outramento - e outramento se dando no tempo - que se insere a autobiografia de Leiris. O si-mesmo como um outro é este si-mesmo que se constitui na relação com o outro, com o fora de si, e é este si-mesmo que se identifica justamente ao se tornar outro.

E neste ponto, volto ao conto de Pessanha, em que podemos notar em Z duas confluências: por um lado, seu anseio em se tornar "humano", em possuir um eu, uma superfície de registro, memórias e hábitos do mundo e, por outro, a incapacidade de se completar, de fugir do "esvaziamento". Ou seja, duas tendências que se ligam: 1) Z não consegue ter memória, não consegue registrar, deixar rastros; e 2) Z não consegue ser preenchido pelo outro. Não há outro que de fato afete Z, o faça “outrar-se”. Nem mesmo a perda da mãe consegue afetá-lo - embora aí seja o momento em que ele parece vislumbrar uma possibilidade de mudança, de "encarnação":

Decidiu que o sumiço da mãe era a constituição de uma ocasião e a hora de uma promissora tentativa de encarnação: a partida da mãe era uma dor e $\mathrm{Z}$ acreditava que se ele fosse capaz de experimentar essa dor poderia então sair do lado de avesso do mundo e ser ejetado para a parte cheia, onde ele encontraria as dadivosas coerções de uma existência. (PESSANHA, 1999, p.26).

Mudança que, no entanto, não chega a se concretizar. Z passa como que incólume pelo mundo; morre sem nem ao menos ter encarnado: Nenhum bombeiro ou instituição humana achou seu corpo: na lápide inexistente não há data de início nem de fim. (PESSANHA, 1999, p.54).

A identidade fugidia de $Z$, como vemos, não é a mesma ipseidade de Leiris. De um certo ponto de vista, alguém poderia contestar que o personagem Z esbarra em uma identidade-idem, uma vez que há a permanência deste caráter efêmero e que o personagem não sofre uma transformação no embate com os outros que lhe cruzam o caminho. De fato, $\mathrm{Z}$ encontra-se enclausurado neste lado exterior do mundo, exilado de qualquer possibilidade de solidificação 
terrena, em um movimento próximo ao da esquizofrenia. ${ }^{5}$

Contudo, prefiro afirmar ainda aqui que, enquanto mesmidade, Z só encontra um núcleo de fluxo puro, uma espécie de "nunca" absoluto. Ou seja, o que há de fixo em Z é ainda tudo de menos fixo que se pode ter: o vazio, o nada, o fluxo, o jorro, a impermanência, o caos. O núcleo unificador e permanente em $\mathrm{Z}$ é a própria fugacidade ou o vazio. Fugacidade esta encarnada no ritmo das frases, nos seus encadeamentos, na velocidade acelerada do texto, em que as cenas se sucedem quase que sobrepostas. Imagens que mal chegam a se formar e logo desaparecem, dão lugar a outras que novamente desaparecem... e assim sucessivamente.

Acredito que, em "Deslocamento", estamos diante do que Ricoeur chama de "casos limites de dissolução da identidade-idem" (RICOEUR, 1988, p.304). Casos que favorecem não só a configuração da narrativa, mas a oportunidade de reconfiguração do próprio leitor: uma figuração do si do leitor na relação do este "outro" da obra. São encontros que algumas obras literárias nos proporcionam, a ocasião de nos depararmos com nossa própria não-permanência, como diz Ricoeur, "a necessidade de passar pela prova desse nada da identidade-permanência”, nada ao qual pertencemos. Nesta medida, até que ponto o encontro com $\mathrm{Z}$ não nos põe diante do nosso próprio exílio, ou não nos joga nele, fazendo-nos experimentar uma despertença radical ao mundo enquanto mesmidade?

\section{Referências}

GAGNEBIN, J.-M. Uma filosofia do cogito ferido: Paul Ricoeur. In: Estudos Avançados, v.11, n.30, USP, 1997, p.261-272.

LEIRIS, M. A idade viril. Tradução de Paulo Neves. São Paulo: Cosac Naify, 2003 (do original em francês L'Âge d'Homme, 1946).

PELBART, P. P. Da clausura do fora ao fora da clausura: loucura e desrazão. São Paulo: Brasiliense, 1989.

\footnotetext{
Refiro-me aqui ao conceito de esquizofrenia desenvolvido por Deleuze e Guattari - em O Anti-Édipo e Mil Platôs. Conceito também trabalhado nestes termos, e no diálogo com Blanchot e Foucault, por Peter Pál Pelbart em Da Clausura do Fora ao Fora da Clausura. O indivíduo louco seria aquele que permanece enclausurado no fora. Há grandes ressonâncias entre o exílio de que fala Juliano Pessanha e o conceito de fora - desenvolvido primeiramente por Blanchot. No entanto, implicaria em um grande desvio e em um outro enfoque, o que não terei como fazer nos limites deste trabalho.
} 
Annita Costa Malufe

PESSANHA, J. G. Sabedoria do nunca. Cotia: Ateliê Editorial, 1999.

RICOEUR, P. L’identité narrative. In: Esprit, juillet-août, 1988, p.295-304.

L’identité narrative. In: Revue des Sciences Humaines, n.221, janvier-mars, p.3547, 1991.

. A questão da ipseidade (prefácio). In: O si mesmo como um outro. Tradução de Lucy Moreira Cesar. Campinas: Papirus, 1991.

STAROBINSKI, J. Le style de l'autobiographie. In: Poétique 3. Paris: Seuil, 1970, p.257265.

Recebido para publicação em 25 de junho de 2008.

Aceito para publicação em 11 de dezembro de 2008. 